\title{
Genetic investigation into an increased susceptibility to biliary atresia in an extended New Zealand Māori family
}

Sophia R. Cameron-Christie ' D, Justin Wilde ${ }^{2}$, Andrew Gray ${ }^{3}$, Rick Tankard ${ }^{4,7}$, Melanie Bahlo ${ }^{4,7}$, David Markie ${ }^{5}$, Helen M. Evans ${ }^{6}$ and Stephen P. Robertson ${ }^{1 *}$

\begin{abstract}
Background: Biliary atresia (BA), a fibrosing disorder of the developing biliary tract leading to liver failure in infancy, has an elevated incidence in indigenous New Zealand (NZ) Mãori. We investigated a high rate of BA in a group of children $(n=12)$ belonging to a single Māori iwi (or 'tribe', related through a remote ancestor).

Methods: Population and geographical data was used to estimate the rate of BA in Māori sub-groups, and a pedigree linking most of the affected children was constructed from oral and documented history. Array genotyping was used to examine hypotheses about the inheritance of a possible genetic risk factor, and the history of the affected population, and Exome Sequencing to search for candidate genes.

Results: Most of these affected children $(n=7)$ link to a self-reported pedigree and carry a 50-fold increase in BA risk over unrelated Māori $\left(X^{2}=296 P<0.001,95 \%\right.$ Cl 23-111). Genetic analysis using FEstim and SNP array genotypes revealed no evidence for elevated consanguinity between parents of affected children (FEstim: $F(2,21)=0.469$, $P>0.63)$. Genome-wide quantitation of intervals of contiguous, homozygous-by-state markers reached a similar conclusion $(F(2,399)=1.99, P=0.138)$. Principal component analysis and investigation with STRUCTURE found no evidence of increased allele frequency of either a recessive variant, or additive, low-risk variants due to reproductive isolation. To identify candidate causal factors, Exome Sequencing datasets were scrutinised for shared rare coding variants across 8 affected individuals. No rare, non-synonymous, phylogenetically conserved variants were common to 6 or more affected children.

Conclusion: The substantially elevated risk for development of BA in this subgroup could be mediated by genetic factors, but the iwi exhibits no properties indicative of recent or remote reproductive isolation. Resolution of any risk loci may rely on extensive genomic sequencing studies in this iwi or investigation of other mechnaisms such as copy number variation.
\end{abstract}

Keywords: Biliary atresia, Exome sequencing, Population genetics, Paediatric disease

\section{Background}

Biliary atresia (BA) is a phenotype of unknown, likely complex, aetiology characterized by congenital, fibrotic obliteration of bile ducts that evolves over the late fetal and early infant periods of development. It is the most common reason for paediatric liver transplant referral [1] and leads to liver failure and death without early

\footnotetext{
* Correspondence: stephen.robertson@otago.ac.nz

${ }^{1}$ Department of Women's and Children's Health, Dunedin School of

Medicine, University of Otago, Dunedin 9054, New Zealand

Full list of author information is available at the end of the article
}

surgical intervention [2]. BA usually presents as an isolated clinical phenomenon but can be a component of a syndromic entity with major malformations [3] and biliary cysts [4], leading to the classification of the disease into multiple categories [5, 6]. The heterogeneity of its presentation in a variety of syndromes, and the inconsistency of correlative factors between different studies, suggests it is not likely to be a single disease with a unifying aetiology, but more a phenotype with multiple contributing factors converging on a similar pathology [5]. 'Isolated BA', when BA occurs in isolation from other

(c) The Author(s). 2018 Open Access This article is distributed under the terms of the Creative Commons Attribution 4.0 International License (http://creativecommons.org/licenses/by/4.0/), which permits unrestricted use, distribution, and reproduction in any medium, provided you give appropriate credit to the original author(s) and the source, provide a link to the Creative Commons license, and indicate if changes were made. The Creative Commons Public Domain Dedication waiver (http://creativecommons.org/publicdomain/zero/1.0/) applies to the data made available in this article, unless otherwise stated. 
non-hepatic or biliary symptoms, is the most common form of the disease [7]. The influence of environmental factors is implied by possible correlations between seasonality and disease onset in some cohorts [8-14] (although evidence is lacking in others $[7,15-22]$ ), putative associations with viral infections [23-26], the isolation of a plant toxin that causes the disease in livestock of multiple species [27, 28], and evidence of greater risk in non-urban children [8] and those resident in regions with lower population density [8]. Genetic factors have also been implicated in isolated BA, including a chromosome 10q24.2 region identified by Genome Wide Association Studies (GWAS) in both SE Asian and European populations with an odds ratio of 1.45-1.77 [29-31]. However, no highly penetrant genetic factors involved in the isolated form of the disease have been identified to date.

There are well-replicated differences in the prevalence of BA, both between ethnically different populations [12, 21, 32-35], and between ethnic groups living within the same region [36, 37], and the established predisposition to this disease in New Zealand Mãori which was re-evaluated recently (author HME, In press, [38]). Elevated rates are found in certain populations across different countries, climates and socio-economic contexts, with particularly high rates in East-Asian [11, 21, 22, 32, 39-43] and Polynesian groups [14, 18, 35, 44], including New Zealand Māori [38]. A difference in response to treatment has also been observed in African-Americans [45], who also have a higher rate of BA than European Americans $[9,46]$. Together these data suggest that ethnicity-specific, possibly genetic, risk factors influence the incidence and course of this disease.

Māori are the indigenous population of New Zealand, descended from Polynesian explorers c.750 years ago [47]. During the migration of large numbers of Europeans in the early nineteenth century, the Māori population declined precipitously due to introduced diseases and conflict $[48,49]$. Subsequently the population has grown to over 600,000 people, living in NZ and overseas. There has been substantial admixture with post-colonial settlers of mainly European descent [50], although approximately half of those who identify as Māori do not also identify with another ethnicity [51]. Studies three decades ago reported a 10-fold increase in the rate of BA in Māori relative to NZ Europeans [52]. Over the last two decades, mandatory referral of all cases of BA to a national centre for treatment (Starship Children's Health, Auckland) has facilitated the recalculation of the risk for this disorder amongst Māori to approximately 3-fold over that observed in NZ Europeans [38]. This recent study also found that BA in children with Māori ancestry is qualitatively different from those of European-only descent, in that Māori children with BA are more likely to be effectively palliated by the Kasai procedure, and hence develop a requirement for liver transplant much later.

An iwi (often translated as "tribe" but also the less structured "people" [53]) is the largest unit of Mãori society operating as both a social and legal distinction. Identification with an iwi is a cultural connection that also signifies common biological ancestry [49] back to the original Polynesian founders of New Zealand [54]. This ancestry is recorded by Mãori through detailed whakapapa ('genealogy') as a fundamental aspect of their culture. Māori membership of an iwi, along with smaller societal units such as hāpu ('clan') and whanau ('extended family') are therefore of genealogical relevance. However, Māori social organisation has been dynamic and adaptive prior to, and after European colonisation [53, 55]. Historical evidence shows significant geographical movement and intermarriage of the communities who now identify as iwi $[56,57]$. This paper investigates BA in two New Zealand iwi, with shared history and intermarriage (referred to as a single iwi here), named Ngāiterangi and Ngāti Ranginui. A much greater number of BA cases than expected, based on NZ prevalence rates, has been reported in this iwi over the last twenty-five years.

We hypothesise that the elevated rate of $\mathrm{BA}$ in the iwi is due to a genetic susceptibility. We show that the iwi as a whole does not exhibit characteristics of reproductive isolation, making it unlikely that a major shift in the allele frequency of many low-risk alleles could have occurred by drift to confer a susceptibility to the development of BA. These observations are congruent with a model that proposes that a dominantly-acting, low-penetrance susceptibility factor could explain this cluster of BA cases.

\section{Methods \\ Ethics}

All subjects were ascertained by physician-initiated referral and consented to participate under a protocol approved by the Southern Regional Ethics Committee $(13 / \mathrm{STH} / 56)$.

\section{Patient ascertainment and ethnicity}

Patient information was ascertained from the national registry of BA patients and curated by one of the authors (HME). Patients were classified as Māori following interview to ascertain a prioritized ethnicity, a hierarchical system commonly used in NZ to attribute a single ethnicity to those with multiple contributing ethnicities. In this system, Māori ethnicity is classified as the highest hierarchy. Mothers of affected iwi individuals retrospectively self-reported their health status and any medical issues of note during the course of their pregnancies. 


\section{DNA genotyping and sequencing}

ES was performed and SNP array data was genotyped for the following individuals within the iwi (see iwi description below): all living, affected individuals (J-5 to J-7 and I-1 to I-5) and their parents (with the exception of the father of J-5), the I-1 sibling with a choledochal cyst, the mother of J-1, and the parents of J-4. DNA extraction from blood was performed using Wizard ${ }^{\circ}$ Genomic DNA Purification Kit from Promega. FFPE DNA extracted by Zymo FFPE DNA miniprep and Zymo purification kit (ZR-96 DNA Clean \& Concentrator ${ }^{\mathrm{mm}}-5$ ) was used for FFPE samples. Genotyping was performed using the Omni1-Quad and Omni5 chip platforms (Illumina) and Exome Sequencing (ES) (Roche SeqCap EZ2, Agilent SureSelect Human AV4, and AV4 + UTR Exon capture chips) was performed by Otogenetics (Atlanta, GA, USA) on the Illumina HiSeq 2000 platform.

FASTQ files were aligned, processed and called on a pipeline consistent with the Genome Analysis Toolkit (GATK) Best Practices [58], and used BWA-MEM [59] for alignment, Picard for sorting and marking duplicates, and GATK IndelRealigner for indel realigning followed by base quality score recalibration and GATK's Haplotypecaller for individual variant calling followed by joint genotyping with GenotypeGVCFs to produce a multi-sample Variant Call Format (VCF) file. Variant annotation performed with SNPeff [60]. Over the patient group, variants were fitted to either a monoallelic (dominant) model or a biallelic (recessive) model.

\section{Population data}

Rates of BA across the entire iwi were determined using population estimates from census data of New Zealanders citing membership of the iwi who were born from 1988 onwards, a period for which census and national BA data were available and which incorporates the period during which the iwi children with BA were born. Population size estimates for affected Pedigree $\mathrm{J}$ individuals (see iwi description below) were estimated as $\sim 850$ people born in the last 30 years, based on historical records of founder pair J's children and the growth of the Mãori population since the birth of those children (Additional file 1: Table S1).

\section{Software}

STRUCTURE and EIGENSOFT's Principal component analysis (PCA) were used to investigate population structure in the samples. STRUCTURE is an algorithm that uses Bayesian clustering to both estimate allele frequencies for a given number of populations, and assign samples to those populations, without a priori information about the samples' expected groupings. STRUCTURE was run iteratively over 10 populations, each with 5 iterations and random seeds. StructureHarvester [61] was used to determine the most likely number of discrete populations (K) across the whole cohort using data generated by STRUCTURE [62]. CLUMPAK [63] was used to summate and visualise the data for the selected K-value (population number). EIGENSOFT uses PCA to define discrete patterns across many dimensions of data (in this case, $>7000$ genetic markers). Germline [64] was used to call runs of markers for homozygosity analysis. Allele frequencies used in FEstim [65] were estimated using Plink [66] from 28 unrelated Māori.

\section{Statistical analysis}

$\mathrm{R}$ Software [67] was used for statistical analysis of FEstim and homozygous-by-state (HBS) data, while Stata 14.2 [68] was used for other statistical analyses including calculating relative risks. Incidence rate ratios were obtained from Poisson regression using calendar month or season (quartiles of January-March, April-June, JulySeptember, and October-December) while adjusting for year as a continuous predictor. Probability that the risk of BA is altered by birth month was expressed using the Wald test [69, 70]. For one-sided statistical analyses (Chi-squared, Wald) $P<0.05$ indicates threshold of statistical significance, for two-sided (two-sided T-tests), $P<0.025$ indicates threshold of statistical significance (signficance $P<0.05$ when accounting for both tails).

\section{Description of iwi cluster and pedigree structure}

Over the period 1991-2009, incidental note was made of a high rate $(n=7)$ of BA in Māori children resident in the Bay of Plenty region of New Zealand, on the east coast of the North Island. Some family members were related to other historical BA cases from the area, and also to another affected child born elsewhere in New Zealand. These family members identified as part of two Bay of Plenty iwi, which will be referred to as 'the iwi' singular for brevity. At the 2013 census, 3.1\% of all Mãori identify as part of this iwi, as well as $11.6 \%$ of Mãori who were resident in the Bay of Plenty [51], making them the 3rd and 5th most common iwi reported in this region. However, all the children born with BA in this Bay of Plenty cluster identified in this iwi except for one (I-5, Fig. 1 \& Fig. 2), and this child reported close geographical and familial connections to other affected children. Five other affected individuals living elsewhere in NZ also had whakapapa connections to the iwi and were also born during the same time period.

Extensive whakapapa (recounting of lineage and familial relationships) by family members was used to construct a pedigree of the seven children with known relatedness (Fig. 1, J-1 to J-7), extending back seven generations to a Māori-European founder pair in the early nineteenth Century (Founder Pair J). This extended family (denoted 'Pedigree J' in this work) in the context of the wider 


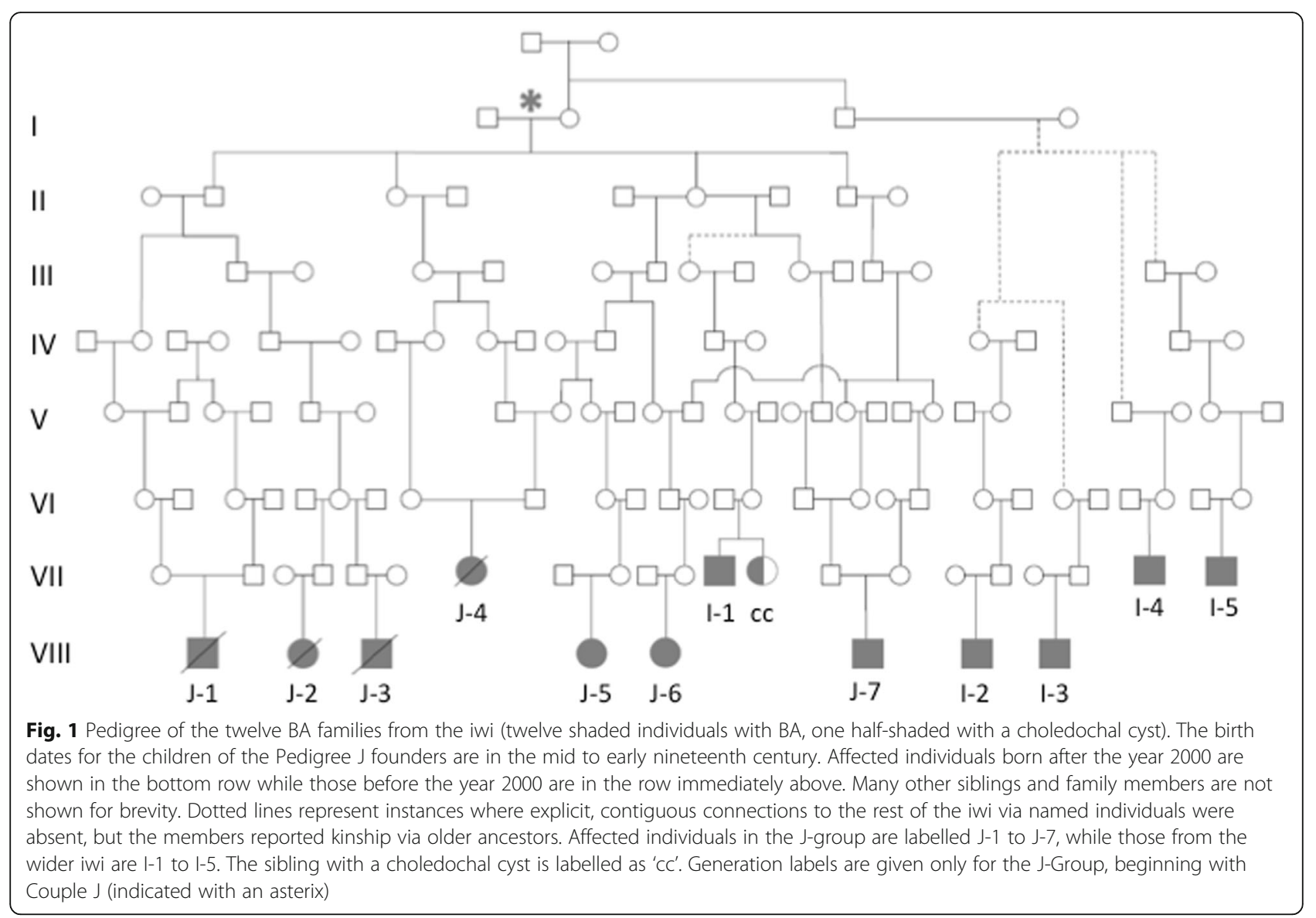

pedigree is shown in Fig. 1. The remaining five affected individuals (I-1 to I-5) could not be explicitly linked to this pedigree by unbroken lines of ancestry but nevertheless can be considered to be related to the iwi with high confidence given the centrality of whakapapa and lineage to Māori culture.

This entire group of 12 affected individuals are therefore considered to be ancestrally connected. Eleven of these individuals had isolated BA, while one (J-2) was excluded from analysis because they presented with syndromic BA with co-existing complex congenital heart disease in the context of a history of poorly controlled maternal diabetes during pregnancy. They were excluded from genetic analysis, but were included in calculations of population incidence figures in keeping with previously published literature, as syndromic BA is not distinguished from non-syndromic presentations in most population-wide studies of the disorder. A thirteenth individual, who is the sibling of an individual with BA, underwent surgery for a congenital choledochal cyst (CC) but had no atresia of the bile ducts. This child was not included in calculations of BA incidence but had ES and array data collected. Apart from this instance there were no instances of recurrence of BA among 20 siblings of affected individuals (by 2009).
Furthermore, there were no cases of BA reported from within the iwi or pedigree prior to 1991, even after extensive liaison and questioning with the extended family iwi kuia and kaumatua (elders) and their constituent whānau (extended families, friends and supporters).

\section{Results}

The clinical observation of an apparently elevated rate of BA prompted us to formally calculate the incidence of BA in this iwi. The rate of BA was estimated relative to that observed in all Māori who did not identify as a member of the iwi. For this estimation, the affected individuals in the iwi were divided into two groups; those that could name shared ancestors through unbroken lineages (J-1 to J-7 or "Group J"), and a broader group that included the pedigree and also those who had connections to the iwi but could not cite them explicitly (I-1 to I-5). Census data from 2013 of living individuals born since 1988 was used as a denominator for estimating rates because these data covered the period of all affected iwi births and included iwi identification. No new BA cases had been reported in the iwi since the initial 2009 observation of the cluster. The population size of the affected generation descended from Couple J 

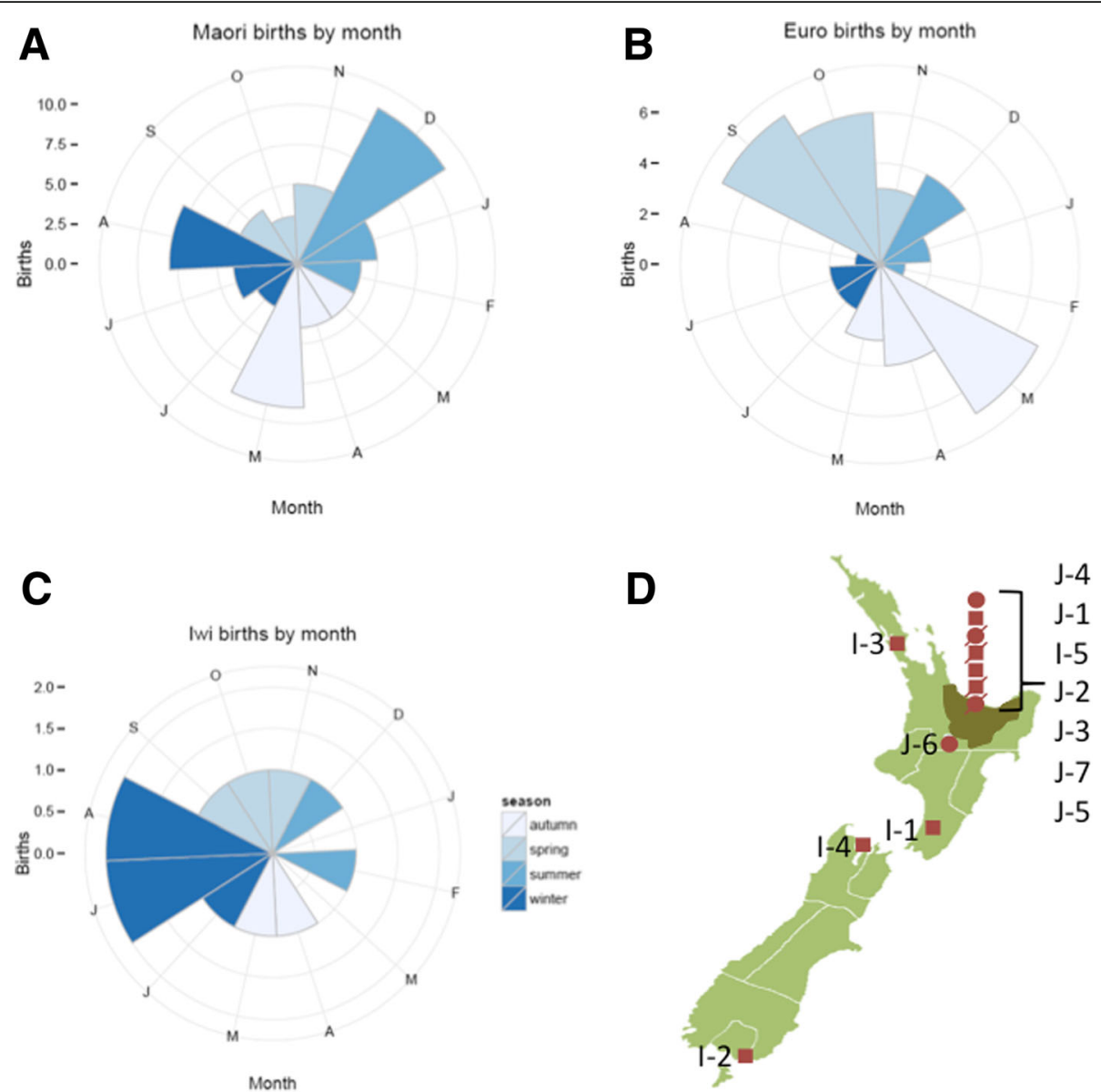

Fig. 2 Rose plots indicating the rate of BA births by month for a Māori, b European and c Individuals from the iwi from New Zealand, with colours indicating the Southern Hemisphere seasons (see key on diagram). d Map of New Zealand with the Bay of Plenty region shown in dark green, and birth places of children shown in dark red (circles for female, squares for male, and strikethroughs for deceased individuals). NZ map adapted from LJ Holden, distributed under a CC-BY-SA 3.0 license

(Additional file 1: Table S1) was estimated by beginning with documented numbers of children and extrapolating their offspring at each subsequent generation from the population growth rates of Māori at each generation [48]. This assumes that an average of one in three ancestral couples were from within the same lineage based on the rate of intermarriage calculated empirically in the reported pedigree.

Excluding the affected individuals who identify as part of the iwi, 49 children with Māori ancestry were born with BA in the same period as the iwi BA cases, from a population $\sim 30$ times larger than the iwi population under study. Over the same period, 43 children of European ethnicity were diagnosed with BA. This translates to a rate of BA in the wider iwi of 1 in 903 live births, compared to a rate of 1 in 6110 in the general Māori population and 1 in 22,228 in the NZ European population. The incidence of the disorder in the central pedigree (Group J) as defined in Fig. 1 is even higher than the wider iwi, estimated at 1 in 121 .
Relative rates are shown in Table 1, which shows the ratio of $\mathrm{BA}$ incidence in the iwi and sub-groups compared to relevant control populations; multiple ratios for the J-Group are shown, comparing them to the iwi and to the Māori population whether or not the iwi is included in this control group. Children who identify as a member of the iwi have a 7-fold greater risk of BA than Māori children in New Zealand who are not part of this iwi (RR 7, $X_{1}^{2}=44.2,95 \%$ Confidence Interval (CI) $\left.4-13, P<0.001\right)$. However, Pedigree J individuals have a 19 -fold greater risk than iwi children who are not part of the pedigree (RR 19, $X^{2}{ }_{1}=42.69,95 \%$ CI 6-64, $\left.P<0.001\right)$ and a 50-fold greater risk of BA compared to non-iwi Māori (RR 50, $X^{2}{ }_{1}=$ 296, 95\% CI 23-111, $P<0.001)$. In contrast, iwi individuals outside the central pedigree have a 2.7 times increase in BA rates compared to non-iwi Mãori $\left(\chi^{2}{ }_{1}=\right.$ 3.93, 95\% CI 1-7, $P=0.048$ ). As expected from previous reports on the incidence of BA in New Zealand, and in Asian and Pacific populations, Māori have a significantly higher risk of BA compared to Europeans 
Table 1 Relative risks (RR) of BA in query populations compared to control populations

\begin{tabular}{|c|c|c|}
\hline Query population & Control population & Relative Rate \\
\hline $\begin{array}{l}\text { J-group Only } \\
(n=7 / 843)\end{array}$ & $\begin{array}{l}\text { Iwi (excluding J-group) } \\
(n=4 / 9079)\end{array}$ & $\begin{array}{l}\text { RR: } 19 \\
P<0.001, \times 2=42.69 \\
95 \% \text { Cl 5-64 }\end{array}$ \\
\hline $\begin{array}{l}\text { J-group Only } \\
(n=7 / 843)\end{array}$ & $\begin{array}{l}\text { All Māori BA (including } \\
\text { non-J-group iwi) } \\
(n=53 / 308,415)\end{array}$ & $\begin{array}{l}\text { RR: } 48 \\
P<0.001, \times 2=284.19 \\
95 \% \text { Cl 22-105 }\end{array}$ \\
\hline $\begin{array}{l}\text { J-group Only } \\
(n=7 / 843)\end{array}$ & $\begin{array}{l}\text { All Māori BA } \\
\text { (excluding iwi) } \\
(n=49 / 299,336)\end{array}$ & $\begin{array}{l}\text { RR: } 50 \\
P<0.001, \times 2=296.12 \\
95 \% \mathrm{Cl} 23-111\end{array}$ \\
\hline $\begin{array}{l}\text { Iwi (Including J-group) } \\
(n=11 / 9922)\end{array}$ & $\begin{array}{l}\text { All Māori BA } \\
\text { (excluding iwi) } \\
(n=49 / 299,336)\end{array}$ & $\begin{array}{l}\text { RR: } 7 \\
P<0.001, \times 2=44.15 \\
95 \% \mathrm{Cl} 4-13\end{array}$ \\
\hline $\begin{array}{l}\text { Iwi (excluding J-group) } \\
(n=4 / 9079)\end{array}$ & $\begin{array}{l}\text { All Māori BA } \\
\text { (excluding iwi) } \\
(n=49 / 299,336)\end{array}$ & $\begin{array}{l}\text { RR: } 3 \\
P=0.048, \times 2=3.93 \\
95 \% \text { Cl } 1-7\end{array}$ \\
\hline
\end{tabular}

(RR $4, \chi^{2}{ }_{1}=63.72,95 \%$ Confidence Interval (CI) 3-6, $P$ $<0.001)$.

Mothers were retrospectively asked about illnesses or exposure to drugs and toxins during pregnancy, but no obvious infections, exposure to toxins or drugs (prescribed medication or non-prescribed substances) were reported during the pregnancies of the iwi BA cases. No mothers had clinically diagnosed autoimmune disorders. The majority of pregnancies took place in the Bay of Plenty, where $40-50 \%$ of the iwi currently live [51] but five of the twelve individuals (J6, I-1 to I-4) were born in other regions across New Zealand (Fig. 2).

In the absence of identifiable environmental factors being reported by the mothers of affected iwi individuals, an environmental link to the BA cluster was further sought focusing on two factors previously associated with the disorder in other populations, seasonality (which varies by study [8-14] [7, 15-22]) and a higher risk of BA in births outside high-density urban centres [16]. To investigate seasonality, the rate of births by month and season was compared within the ancestral groups: all Māori, iwi-identifying Māori and NZ European. As shown in Fig. 2, there was no evidence of differences by birth month for affected iwi individuals (Wald $P=1.00$ ); nor was there evidence of monthly differences for Māori (Wald $P=0.92$ ), Europeans (Wald $P=0.23$ ) or all births combined (Wald $P=$ 0.37). There was also no evidence of differences found for seasonal quartile, (see Methods), with Wald $P=0.98$ for iwi, $P=0.99$ for Māori, $P=0.61$ for Europeans, and $P=0.29$ for all births. Children with BA from the iwi were classified into those born inside or outside main urban areas, as defined by the New Zealand census [51]. Sample sizes are too small to consider a formal test: however, two individuals with BA (17\%) in the iwi kindred were born outside of main urban areas compared to rates of $26 \%$ of Māori women of childbearing age recorded to be living outside main urban areas.

Since these affected individuals were born in widely dispersed geographical locations across New Zealand and a common environmental explanatory factor was not readily evident to explain the clustering of BA in this iwi, this led us to conduct a genetic study in this kindred.

Since consanguinity was explicitly reported between parents of three of the twelve affected individuals (J-1, J-4 and J-7), tests for homozygosity in the other affected iwi children were performed. Where DNA was available from living individuals (J-5 to J-7 and I-1 to I-5), SNP chip data from affected individuals were examined for signals of homozygosity that could indicate parental relatedness, to test whether those with no known parental consanguinity nevertheless showed elevated homozygosity. In affected iwi individuals, elevated homozygosity was investigated by comparison to their parents (representing a group of individuals from the same population, without $\mathrm{BA}$ ) and a group of parents of children with BA but no connection to the iwi using both parametric (FEstim) and nonparametric methods (homozygousity-by-state). FEstim [65] estimates homozygosity across genome-wide markers using a hidden Markov model with the assumption of linkage equilibrium. FEstim homozygosity estimates were compared to the levels of expected homozygosity, given the allele frequencies from the broad population under study. Continuous runs of markers that are homozygous-by-state (HBS) were also identified within samples because larger segments could indicate more recent consanguinity. Although there is a decrease in both Identity-by-descent (IBD) segment size as measured in centiMorgans (cM) and number of segments with increasing numbers of meioses, relationships between parents as remote as 5th cousins are detectable using this approach [71].

One affected child (I-1) whose sibling had a choledochal cyst was expected to show little or no measurable homozygosity as one parent was of European ancestry and was born outside of New Zealand. It had been assumed a priori that their affected status would be unlikely to be explained by a homozygous recessive allele. As a result they were not included in the statistical comparisons below so as not to bias the affected group towards lower estimates of homozygosity.

No significant difference was found in FEstim scores across the three Māori groups (affected children, iwi parents and Māori parents of affected children outside the iwi) (ANOVA, $F(2,21)=0.469, P=0.63$ ). Runs of HBS were compared between offspring of parents from within the iwi with known consanguinity, compared to those from iwi parents with no reported ancestral connection. Only those samples with reported parental consanguinity (J-7 and his father) were found to have runs of homozygosity over $11 \mathrm{cM}$ (Fig. 3). Samples from children with 


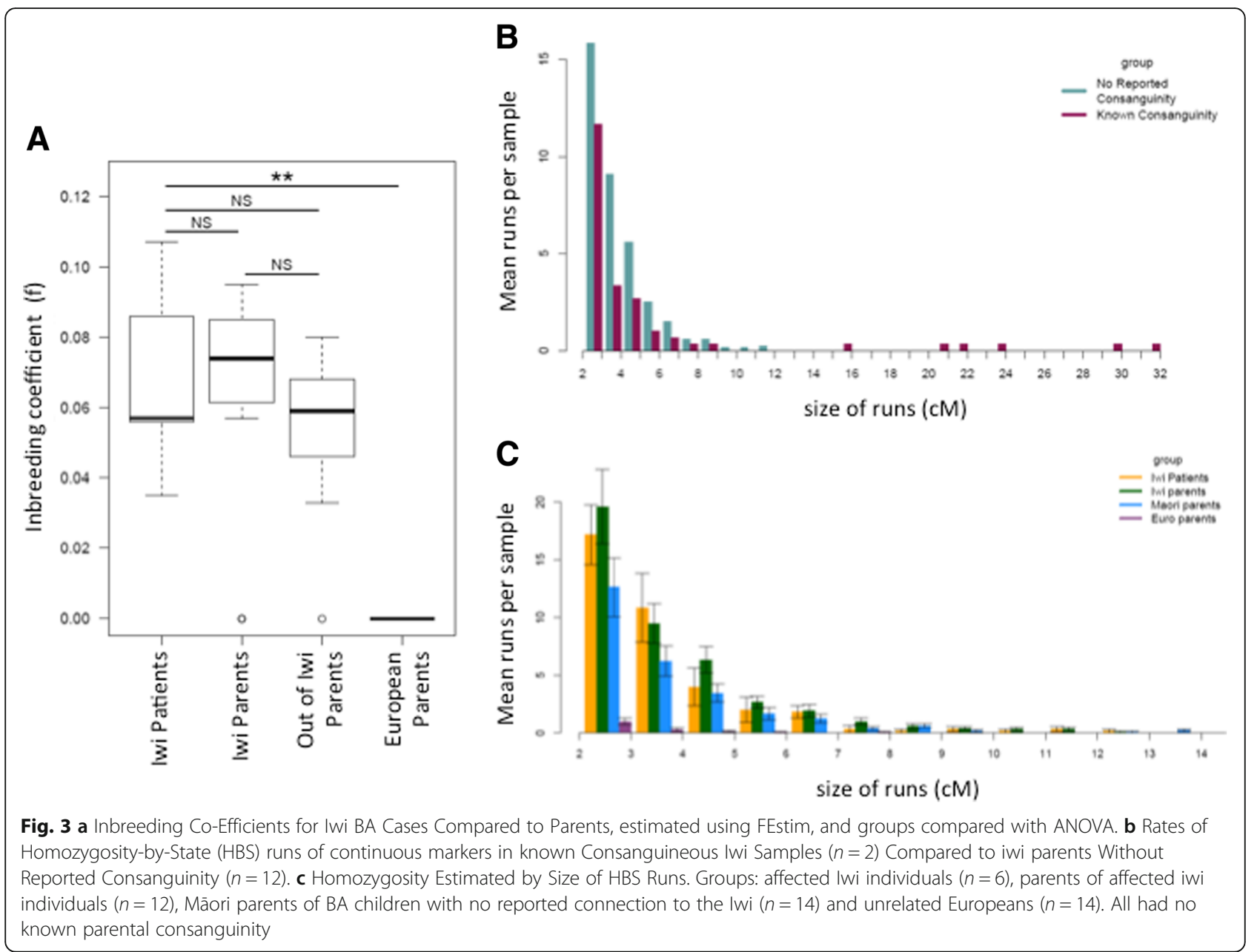

BA without known parental consanguinity were then compared to the two unaffected parental groups (Fig. 3). Mean size of HBS runs did not differ between these three sample groups (ANOVA, $F(2,399)=1.99, P=0.138$ ). Of the five affected subjects without reported consanguinity (J-5 to J-6 and I-2 to I-5), only a single run above $11 \mathrm{cM}$ was detected in one affected individual with no parental consanguinity, but whose parents both belonged to the iwi, possibly indicating distant consanguinity. Using both of these measures it can be concluded that individuals with $\mathrm{BA}$ in the iwi do not have elevated homozygosity compared to their parents or to Māori from outside the iwi.

Since an elevated rate of BA compared to other Māori has been identified only in this iwi (no clusters have been reported in other NZ areas or communities), a recessive variant whose allele frequency has become elevated by genetic drift would be more likely to be specific to the iwi if the population was genetically isolated. To test whether there is population structure (the presence of genetic diversity correlating to sub-populations) between members of the iwi and other Māori, all Māori parents for whom genotyping data were available $(n=28)$ were divided into those who were part of the iwi and/or pedigree J and those who were not. EIGENSOFT's smartpca [72] and STRUCTURE [62] were used to investigate population differences between the two groups (see methods for a description of STRUCTURE's application). Data from seven individuals of European ancestry were included to facilitate the detection of European admixture that was expected in most of the samples from Māori analysed in this study. The expectation was that admixed samples would cluster closer to Europeans in PCA and that such admixture would be accurately identifiable when using STRUCTURE.

The first eigenvector identified in the dataset from the PCA analysis corresponded to European ancestry (Fig. 4). There was no significant difference between iwi samples and non-iwi Māori samples along the second eigenvector nor the subsequent vectors, such as would be expected if these groups exhibited substantial population structure. Two populations (correlating to Māori and European samples) were also shown to be the best hypothesis to explain the STRUCTURE data using the Evanno method through StructureHarvester [61]. Population structure 


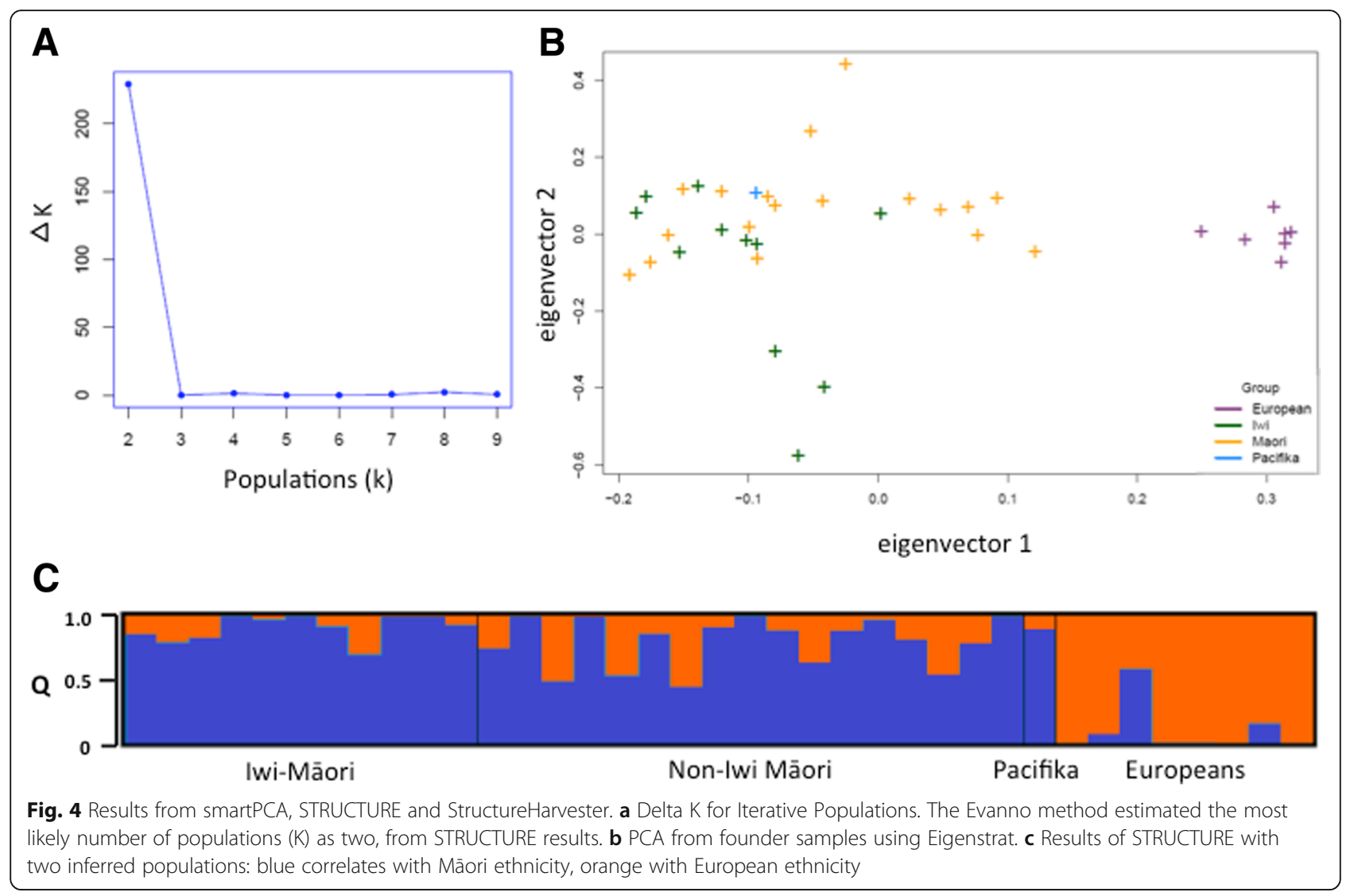

was not detected in the Mãori samples outside of the expected European admixture that was common across this entire group. The degree of European admixture between the in-iwi and out-of-iwi parents was not significantly different under a two-side t-test, in which 0.025 is classed as significant (Welch Two Sample t-test, $t=2.30, \mathrm{df}=26.49, P=0.03)$ between these two populations. Three European samples were predicted to have Māori admixture; the highest (predicted admixture proportion of 0.58 ) was in a sample that was determined to have been mislabelled, and whose original records gave her ethnicity as Māori. One of the others, with 0.07 proportion of predicted admixture, was known to have two Māori great-great-great grandparents. The third unexpectedly admixed sample (predicted admixture $=0.16$ ) remains unexplained, but as a New Zealand European, may have unreported Māori ancestry.

The unremarkable rates of homozygosity in affected children and the lack of evidence of an iwi-specific genetic bottleneck indicative of reproductive isolation, suggests that a founder effect leading to a single recessive factor is unlikely to explain a genetic component of BA susceptibility in the iwi. As an alternative, a model proposing a dominantly acting variant of low penetrance that could account for the 50-fold increase in BA within the pedigree was tested. As opposed to common alleles of minor effect that are often non-coding, variants associated with substantial influence on the penetrance of oligogenic traits are frequently located in the coding genome (including coding variants in other complex disorders such as hypercholesteremia [73], and family-specific, low-penetrance variants associated with rare conditions such as oral clefts [74]) Exome Sequencing (ES) of all living, affected children in the iwi (J-5 to J-7 and I-1 to I-5) and their parents was performed, except for one parent where no DNA was available. Using this dataset, a susceptibility variant was hypothesized to have the following characteristics. These are listed in order of priority): (a) present in all affected members of the J-group ( $n=4$, with living, and DNA available for parents of J-4 to inform her possible genotypes), and at least 6 members of all affected iwi individuals ( $n=9$, including I- 4 via parental genotypes); (b) rare global MAF $(<0.01)$ as reported by either the Exome Variant Server [75] or dbSNP (version hg19_137) [76]; (c) is phylogenetically conserved and/or there is a effect on a protein (predicted by SNPeff as a missense or protein-truncating variant); (d) rare ( $<0.1 \mathrm{MAF})$ in Māori OR private to the iwi. The Māori frequency could only be estimated from the non-transmitted alleles of BA parents 
as no Māori genome-wide datasets are publically available; (e) affects a coding region of the genome (including $+2 /-2$ bases from a splice-site boundary).

Exome coverage across all affected iwi individuals was above 10 reads for at least $97 \%$ of all targeted bases. No variants under a monoallelic or biallelic model of inheritance were identified that fulfilled all of the criteria listed above. Māori MAF, for which only limited information was available, was not used as an exclusionary factor as it did not distriminate between any variants already excluded by other means. No variant was observed in 5 or more individuals with BA, that exhibited at least moderate levels of phylogenetic conservation (scoring above 0.5 using phastCons [77]), and was predicted to be protein-altering in ANNOVAR [78]. Variants present in all available J-Group affected individuals were also examined (J-5, J-6, J-7, and either or both of J-4's parents), with no requirement to be present in other samples. One variant fitted the remaining criteria, a known polymorphism in ERAP1, rs118132132, also carried by I-2. rs118132132 alters a highly conserved amino acid and is reported only in East-Asian populations [79], where it is present at a MAF of $1 \%$. The absence of this candidate in $4 / 9$ affected iwi individuals despite its relatively high frequency in East-Asian populations makes it implausible that it could explain this unusual BA cluster.

\section{Discussion}

BA has a greater incidence in South-East Asian and Pacific populations compared to Europeans, but an elevated rate has only recently been rigorously demonstrated for New Zealand Māori. Due to the informal centralised referral of all cases of BA in New Zealand, a cluster of cases in the Bay of Plenty region was recognised, and multiple affected families identified reported distant relatedness to each other (the pedigree or J-group) or identified their lineage to the same two overlapping iwi. This iwi represents a unique opportunity to study BA in a cohort which likely shares a much stronger common genetic etiology. Taking the iwi and the pedigree as delineated groups, it was found that significantly more children with BA were born into these groups than would be expected in the Māori population not connected to the iwi - 6.8 times the rate of $\mathrm{BA}$ in the wider iwi and 50-fold in the pedigree. No unusual environmental factors were reported that were common to all or most affected children, many of whom were born in widely dispersed locations across the country. Seasonality was not found to be associated with $\mathrm{BA}$ as it has been in other populations.

Regional geographical clusters of BA have not been reported before, apart from a high rate reported in French Polynesia $[14,35]$ and a slight increase in one Scottish region [80], although the NZ iwi risk is an order of magnitude greater than the incidence in these areas. Of particular note is that all of the affected iwi children were born in the last quarter-century, suggesting a recently encountered environmental factor could have precipitated the development of BA in the presence of a genetic predisposition. Identifying environmental factors retrospectively is challenging, especially for a relatively small cohort, but studies are underway to study possible correlations with BA in the iwi.

The sporadic occurrence of BA within the iwi and pedigree makes it difficult to prioritise a genetic model to search for these hypothesised factors. Binary traits can occur both because of discrete, Mendelian factors or due to the presence of a liability threshold around which the additive risk from many loci leads to the expression of a phenotype. The study design pursued here can only identify discrete Mendelian factors, as additive risk contributed by many loci needs to be investigated with much larger sample sizes and is best pursued with a GWAS design.

In this iwi there was no evidence for elevated rates of homozygosity in most affected individuals whose parents had no known consanguinity, though high levels of homozygosity were noted generally in affected and unaffected Māori samples from both inside and outside of the iwi. This suggests that if a recessively-acting, high-risk factor is responsible for $\mathrm{BA}$ in this iwi, it is attributable to relatedness to common remote ancestors that is not discernible from the high rate of homozygosity in the Māori population more generally, at least using the genomic tools deployed here. This level of homozygosity is not unusual in populations with a recent history of founder effects, such as seen in present-day Finland [79, 80], Iceland [82] and the Greater Middle East [83]. For instance, similar levels of HBS have been seen in Finnish populations originating from founder groups 300-400 years ago [81], in which $90 \%$ of samples had runs of HBS > $5 \mathrm{cM}$.

Diseases that exist in a binary state (presence/absence of the disease) may be explained by the additive effect of many low-risk alleles [84], the genetics of which can be described using a liability threshold model. Given the sporadic occurrence of the disease, genetic factors with minor influence on the risk of BA are likely to be present in this cohort, similar to the ADD3 SNP identified by previous GWAS [29,30] with an odds ratio of 1.45 in European and East-Asian populations. Such minor risk factors may be transmitted by the relatively high-risk Māori background on which the disease cluster has occurred. It is possible that a confluence of these low-risk factors, already present in the general population, could explain a higher rate of the disease in one genetically connected group. However, a threshold model involving many loci would require an aggregation of many risk alleles in the iwi compared to the parental Māori population. These alleles would also have to be sufficiently numerous or of high enough risk, to increase the rate of BA by $\sim 50$-fold. 
The greater the number of low-risk alleles proposed by a threshold liability model, the greater the divergence between populations must be, and we found no evidence for this in this study. If a liability threshold model accurately applied in this instance, it would require some population history that distinguishes the iwi from other Mãori, such as a founder effect coupled with reproductive isolation from other Māori. Alternatively there would need to be evidence for dramatic selection (such as for a geographically limited pathogen) acting across many loci, or significant admixture with an unidentified population carrying the risk alleles. Likewise, for a recessive factor, the spread of a causal allele from a very distant ancestor across the iwi would usually be accompanied by demonstrable reproductive isolation of the iwi to account for the 50-fold higher rate of $\mathrm{BA}$ in this community compared to the wider population. However, the history of the iwi and the area is indicative of frequent migrations, intermarriages and conflict between diverse groups over the past few hundred years $[56,57]$ and does not support the separation of the iwi from the Māori population. Supporting this historical data, PCA analysis (EIGENSOFT) and Bayesian clustering (STRUCTURE), found no evidence that the iwi demonstrated detectable genetic structure compared to the wider Mãori population. If differential population structure was present between iwi and non-iwi Mãori, the two groups would separate along the second eigenvector in Fig. 4, or a third population correlating with iwi identity would have been found with STRUCTURE (Fig. 4). However, there was no significant difference in the values of the two groups along this second eigenvector, and a hypothesis of only two populations (Māori and European) was shown to be the best hypothesis to explain the STRUCTURE data. This indicates there has been historic gene flow between the iwi and the wider Māori population. This is counter to a hypothesis of genetic isolation favouring an ancestral recessive variant specific to the iwi, or multiple risk variants, leading to susceptibility to develop BA.

An alternative model that was considered here was a factor inherited from a relatively recent common ancestor with the low-penetrance of this factor and/or dependence on environmental modifiers invoked to explain the relatively recent appearance of the phenotype. Using Exome Sequencing (ES), no clear candidate variants were identified under either a dominant or recessive model within the coding genome to support such a model. Further investigation to define which regions of the genome the affected individuals share may reduce the search space for this putative susceptibility conferring factor. Relevant genetic elements that could not be considered as potentially predisposing to the development of BA in this study include intergenic variants, which are not captured for sequencing by the exome approach used here but can effect expression and regulation of one or more genes, and large structural variants that may not be detected with short-read sequencing but could change the copy number of one or more genes. The cluster of BA cases in this iwi represents a globally and historically unique chance to further understanding of the etiology of BA.

\section{Conclusions}

We presented a cluster of biliary atresia cases that to our knowledge is unique in the literature, with up to 50 times the incidence of the disease compared to an already elevated rate in an indigenous, understudied New Zealand Māori population. Despite a complicated population history of bottlenecking and spare consanguinity, we found no evidence of elevated homozygosity across most of the affected children, nor evidence that the affected iwi had a history of reproductive isolation from the wider Mãori population. We proposed that a dominant, low-penetrance variant in combination with environmental factors could explain this pattern of biliary atresia, possibly inherited by most of the affected children within the two centuries spanned by their pedigree. However, Exome Sequencing of all available affected individuals did not uncover a plausible candidate variant under a mono- or biallelic model, and further research is required, such as investigating alternative categories of variation such a copy number.

\section{Additional files}

Additional file 1: Table S1. Estimates of the number of extant descendents of Couple J (DOCX $80 \mathrm{~kb}$ )

\section{Abbreviations}

ANOVA: Analysis of Variance; BA: Biliary Atresia; BWA: Burrows-Wheeler Aligner; Cl: Confidence Interval; cM: centiMorgans; GATK: Genome Analysis Toolkit; GWAS: Genome Wide Association Study; HBS: Homozygosity-by-state; IBD: Identity-by-descent; IBS: Identity-by-state; NZ: New Zealand;

PCA: Principal component analysis; RR: Relative Rate; WES: Whole Exome Sequencing

\section{Acknowledgements}

The authors would like to thank all participants for their support for this work.

\section{Funding}

SRCC was supported by the CureKids Kirsty McDermott Memorial Scholarship. SPR was supported by the Health Research Council of New Zealand and Cure Kids New Zealand. RT was supported by an Australian Postgraduate Award scholarship. MB was supported by an NHMRC Senior Research Fellowship (1002098) and NHMRC Program Grant (1054618). The research was funded by CureKids and the Health Research Council of New Zealand, but the funding bodies were not involved in the design of the study or the collection, analysis and interpretation of data or the writing of the manuscript.

\section{Availability of data and materials}

The sequencing and genotype datasets generated and analysed during the current study are not publicly available as consent for the use of genetic material and subsequent sequencing and genotype data is limited to the study of biliary atresia, and sharing of genetic data beyond the scope of this study is contingent on re-consent from the participant/s who provided the 
material. Please contact the corresponding author (SR) about the sharing of data for the study of biliary atresia. Census population data for NZ is available through Statistics NZ (http://archive.stats.govt.nz) [51].

\section{Authors' contributions}

All authors contributed to the writing and editing of this manuscript. SRCC performed the majority of the bioinformatics and writing of the manuscript JW identified and supported participants in the study, AG performed and advised statisical analysis, RT and MB made substantial contributions to the conception of the population genetics aspects of the study as well as planning the bioinformatic analyses. Both reviewed and revised versions of the manuscript, DM performed preperatory sequencing bioinformatics and managed the sequencing database, HME was the primary contact with participants, provided clinical guidance and expertise about biliary atresia and study design, and SPR the main supervisor and advisor to the project and a major contact with participants. All authors have read and approved this manuscript.

\section{Ethics approval and consent to participate}

All subjects were ascertained by physician-initiated referral and consented to participate under a protocol approved by the Southern Regional Ethics Committee, (13/STH/56). All individuals gave written consent for DNA research for the purpose of studying BA, or consent was provided by a parent or guardian for underage or deceased individuals.

\section{Consent for publication}

Not applicable.

\section{Competing interests}

The authors declare that they have no conflicts of interest. SRCC would like to declare that since the completion of this study and manuscript, she has accepted a role as AstraZeneca UK, in a position which has no relation to the work described here.

\section{Publisher's Note}

Springer Nature remains neutral with regard to jurisdictional claims in published maps and institutional affiliations.

\section{Author details}

'Department of Women's and Children's Health, Dunedin School of Medicine, University of Otago, Dunedin 9054, New Zealand. ${ }^{2}$ Department of Paediatrics, Tauranga Hospital, Tauranga, New Zealand. ${ }^{3}$ Department of Preventive and Social Medicine, University of Otago, Dunedin 9054, New Zealand. ${ }^{4}$ Population Health and Immunity Division, The Walter and Eliza Hall Institute of Medical Research, 1G Royal Parade, Parkville, VIC 3052, Australia. ${ }^{5}$ Department of Pathology, University of Otago, Dunedin 9054, New Zealand. ${ }^{6}$ Paediatric Gastroenterology and Hepatology, Starship Children's Health, 2 Park Road, Grafton, Auckland 1023, New Zealand. 'Department of Medical Biology, The University of Melbourne, Parkville, VIC 3010, Australia.

\section{Received: 3 January 2018 Accepted: 27 November 2018}

\section{Published online: 18 December 2018}

\section{References}

1. Whitington PF, Balistreri WF. Liver transplantation in pediatrics: indications, contraindications, and pretransplant management. J Pediatr. 1991;118(2): 169-77.

2. Davenport M. Biliary atresia: outcome and management. Indian J Pediatr. 2006;73(9):825-8.

3. Guttman OR, Roberts EA, Schreiber RA, Barker CC, Ng VL. The Canadian pediatric hepatology research G: biliary atresia with associated structural malformations in Canadian infants. Liver Int. 2011;31(10):1485-93.

4. Tanaka H, Sasaki H, Wada M, Sato T, Kazama T, Nishi K, Kudo H, Nakamura M, Nio M. Postnatal management of prenatally diagnosed biliary cystic malformation. J Pediatr Surg. 2015;50(4):507-10.

5. Petersen C, Davenport M. Aetiology of biliary atresia: what is actually known? Orphanet J Rare Dis. 2013;8(1):128.

6. Asai A, Miethke A, Bezerra JA. Pathogenesis of biliary atresia: defining biology to understand clinical phenotypes. Nat Rev Gastroenterol Hepatol. 2015;12(6):342-52.
7. Davenport M, FRCS C, Dhawan A. Epidemiologic study of infants with biliary atresia. Pediatrics. 1998;101(4):729-30.

8. Strickland AD, Shannon K. Studies in the etiology of extrahepatic biliary atresia: time-space clustering. J Pediatr. 1982;100(5):749-53.

9. Yoon PW, Bresee JS, Olney RS, James LM, Khoury MJ. Epidemiology of biliary atresia: a population-based study. Pediatrics. 1997;99(3):376-82.

10. The NS, Honein MA, Caton AR, Moore CA, Siega-Riz AM, Druschel CM. Risk factors for isolated biliary atresia, National Birth Defects Prevention Study, 1997-2002. Am J Med Genet A. 2007;143A(19):2274-84.

11. Nakamizo M, Toyabe S-I, Kubota M, Komata O, Suzuki H, Akazawa K. Seasonality in the incidence of biliary atresia in Japan. Acta Paediatr. 2006;95(4):511-2.

12. Fister $P$, Orel R, Sedmak M, Gvardijančič D, Homan M. Congenital extrahepatic biliary atresia in children in Slovenia - epidemiological retrospective data. Zdravniški Vestnik. 2013;82(2):86-92.

13. Fischler B, Papadogiannakis $N$, Nemeth A. Aetiological factors in neonatal cholestasis. Acta Paediatr. 2001;90(1):88-92.

14. Girard M, Jannot AS, Besnard M, Leutenegger AL, Jacquemin $E$, Lyonnet $S$, Henrion-Caude A. Polynesian ecology determines seasonality of biliary atresia. Hepatology. 2011;54(5):1893-4.

15. Ayas MF, Hillemeier AC, Olson AD. Lack of evidence for seasonal variation in extrahepatic biliary atresia during infancy. J Clin Gastroenterol. 1996;22(4):292-4.

16. Livesey E, Borja MC, Sharif K, Alizai N, McClean P, Kelly D, Hadzic N, Davenport M. Epidemiology of biliary atresia in England and Wales (19992006). Arch Dis Child Fetal Neonatal Ed. 2009:94(6):F451-5.

17. Fischler B, Haglund B, Hjern A. A population-based study on the incidence and possible pre- and perinatal etiologic risk factors of biliary atresia. $J$ Pediatr. 2002;141(2):217-22.

18. Chardot C, Carton M, Spire-Bendelac N, Pommelet CL, Golmard J-L, Auvert B. Epidemiology of biliary atresia in France: a national study 1986-96. J Hepatol. 1999;31(6):1006-13.

19. Houwen RHJ, Kerremans IIA, Vansteenselmoll HA, Vanromunde LKJ, Bijleveld CMA, Schweizer P. Time-space distribution of extrahepatic biliary atresia in the Netherlands and West-Germany. Zeitschrift Fur Kinderchirurgie-Surgery in Infancy and Childhood. 1988;43(2):68-71.

20. Wildhaber BE, Majno P, Mayr J, Zachariou Z, Hohlfeld J, Schwoebel M, Kistler W, Meuli M, Le Coultre C, Mentha G, et al. Biliary Atresia: Swiss National Study, 1994-2004. J Pediatr Gastroenterol Nutr. 2008;46(3):299-307. https:// doi.org/10.1097/MPG.1090b1013e3181633562.

21. Tiao M-M, Tsai S-S, Kuo H-W, Chen C-L, Yang C-Y. Epidemiological features of biliary atresia in Taiwan, a national study 1996-2003. J Gastroenterol Hepatol. 2008;23(1):62-6.

22. Wada H, Muraji T, Yokoi A, Okamoto T, Sato S, Takamizawa S, Tsugawa J, Nishijima E. Insignificant seasonal and geographical variation in incidence of biliary atresia in Japan: a regional survey of over 20 years. J Pediatr Surg. 2007:42(12):2090-2.

23. Fischler B, Ehrnst A, Forsgren M, Örvell C, Nemeth A. The viral Association of Neonatal Cholestasis in Sweden: a possible link between cytomegalovirus infection and extrahepatic biliary atresia. J Pediatr Gastroenterol Nutr. 1998; 27(1):57-64

24. De Tommaso A, Andrade P, Costa S, Escanhoela C, Hessel G. High frequency of human cytomegalovirus DNA in the liver of infants with extrahepatic neonatal cholestasis. BMC Infect Dis. 2005:5:108.

25. Brindley SM, Lanham AM, Karrer FM, Tucker RM, Fontenot AP, Mack CL. Cytomegalovirus-specific T-cell reactivity in biliary atresia at the time of diagnosis is associated with deficits in regulatory T cells. Hepatology. 2012; 55(4):1130-8

26. Riepenhoff-Talty M, Gouvea V, Evans MJ, Svensson L, Hoffenberg E, Sokol RJ, Uhnoo I, Greenberg SJ, Schäkel K, Zhaori G, et al. Detection of group C rotavirus in infants with extrahepatic biliary atresia. J Infect Dis. 1996;174(1):8-15.

27. Harper PAW, Plant JW, Ungers DB. Congenital biliary atresia and jaundice in lambs and calves. Aust Vet J. 1990;67(1):18-22.

28. Lorent K, Gong WL, Koo KA, Waisbourd-Zinman O, Karjoo S, Zhao X, Sealy I, Kettleborough RN, Stemple DL, Windsor PA, et al. Identification of a plant isoflavonoid that causes biliary atresia. Sci Transl Med. 2015;7(286);286ra67.

29. Garcia-Barcela M-M, Yeung M-Y, Miao X-P, Tang CS-M, Cheng G, So M-T, Ngan E-W, Lui VC-H, Chen Y, Liu X-L, et al. Genome-wide association study identifies a susceptibility locus for biliary atresia on 10q24.2. Human Molecular Genetics. 2011;20(5):1048.

30. Tsai E, Grochowski C, Loomes K, Bessho K, Hakonarson H, Bezerra J, Russo P, Haber B, Spinner N, Devoto M. Replication of a GWAS signal in a Caucasian 
population implicates ADD3 in susceptibility to biliary atresia. Hum Genet. 2014;133(2):235-43.

31. Zeng S, Sun P, Chen Z, Mao J, Wang J, Wang B, Liu L. Association between single nucleotide polymorphisms in the ADD3 gene and Susceptibility to biliary atresia. PLoS One. 2014;9(10):e107977.

32. Nio M, Ohi R, Miyano T, Saeki M, Shiraki K, Tanaka K. Five- and 10-year survival rates after surgery for biliary atresia: a report from the Japanese biliary atresia registry. J Pediatr Surg. 2003;38(7):997-1000.

33. McKiernan PJ, Baker AJ, Kelly DA. The frequency and outcome of biliary atresia in the UK and Ireland. Lancet. 2000;355(9197):25-9.

34. Hsiao C-H, Chang M-H, Chen H-L, Lee H-C, Wu T-C, Lin C-C, Yang Y-J, Chen A-C, Tiao M-M, Lau B-H, et al. Universal screening for biliary atresia using an infant stool color card in Taiwan. Hepatology. 2008;47(4):1233-40.

35. Vic $P$, Gestas P, Mallet EC, Arnaud JP. Biliary atresia in French Polynesia - a 10 year retrospective study. Archives De Pediatrie. 1994;1 (7):646-51.

36. Girard M, Jannot A-S, Besnard M, Jacquemin E, Henrion-Caude A. Biliary atresia: does ethnicity matter? J Hepatol. 2012;57(3):700-1.

37. Jimenez-Rivera C, Jolin-Dahel KS, Fortinsky KJ, Gozdyra P, Benchimol El. International incidence and outcomes of biliary atresia. J Pediatr Gastroenterol Nutr. 2013;56(4):344-54.

38. Evans HM, Asher Ml, Cameron-Christie S, Farthing S, McCall J, Robertson SP, Wong H, Morreau PN. Ethnic Disparity in the Incidence and Outcome of Biliary Atresia in New Zealand. J Pediatr Gastroenterol Nutr. 2017;66(2); 218-21.

39. Matsui A, Sasakia N, Arakawa Y, Ishikawa T, Momoya T, Kasano Y, Yanagisawa M, Tsukagoshi N, Kawai T. Neonatal mass screening for biliary atresia: a pilot study in Tochigi prefecture, Japan. Screening. 1993;2(4):201-9.

40. Gu Y-H, Yokoyama K, Mizuta K, Tsuchioka T, Kudo T, Sasaki H, Nio M, Tang J, Ohkubo T, Matsui A. Stool Color Card Screening for Early Detection of Biliary Atresia and Long-Term Native Liver Survival: A 19-Year Cohort Study in Japan. J Pediatr. 2015;166(4):897-902.e891.

41. Lin Y-C, Chang M-H, Liao S-F, Wu J-F, Ni Y-H, Tiao M-M, Lai M-W, Lee H-C, Lin C-C, Wu T-C, et al. Decreasing rate of biliary atresia in Taiwan: a survey, 2004-2009. Pediatrics. 2011;128(3)::530-6.

42. Hung PY, Chen CC, Chen WJ, Lai HS, Hsu WM, Lee PH, Ho MC, Chen TH, Ni $\mathrm{YH}$, Chen $\mathrm{HL}$, et al. Long-term prognosis of patients with biliary atresia: a 25 year summary. J Pediatr Gastroenterol Nutr. 2006;42(2):190-5.

43. Chiu C-Y, Chen P-H, Chan C-F, Chang M-H, Wu T-C. Biliary Atresia in Preterm Infants in Taiwan: A Nationwide Survey. J Pediatr. 2013;163(1):100-103.e101.

44. Shim WK, Kasai M, Spence MA. Racial influence on the incidence of biliary atresia. Prog Pediatr Surg. 1974;6

45. Arva NC, Russo PA, Erlichman J, Hancock WW, Haber BA, Bhatti TR. The inflammatory phenotype of the fibrous plate is distinct from the liver and correlates with clinical outcome in biliary atresia. Pathology - Res Prac. 2015; 211(3):252-60

46. Caton AR, Druschel CM, McNutt LA. The epidemiology of extrahepatic biliary atresia in New York state, 1983-98. Paediatr Perinat Epidemiol. 2004; 18(2):97-105.

47. Whyte ALH. Human evolution in Polynesia: a molecular biological study; 2002.

48. Taupori Mãori - Mãori population change - Population changes. 1769-1840. [https://teara.govt.nz/en/population-change].

49. Glover M, Rousseau B. 'Your child is your whakapapa': Maori considerations of assisted reproduction and human relatedness. Sites: I Social Anthropol Cult Stud. 2007:4(2):117-36.

50. Edinur HA, Dunn PPJ, Hammond L, Selwyn C, Velickovic ZM, Lea RA, Chambers GK. Using HLA loci to inform ancestry and health in Polynesian and Maori populations. Tissue Antigens. 2012;80(6):509-22.

51. New Zealand Census 2013 [http://www.stats.govt.nz/Census/2013census.aspx].

52. Schroeder D, Pease PB. Biliary atresia a review of the Auckland experience. Pediatr Surg Int. 1989;4(2):101-4.

53. Ballara A: Iwi: The dynamics of Māori tribal organisation from c. 1769 to c. 1945: Victoria University Press; 1998

54. Mead HM: Tikanga Māori: living by Māori values: Huia publishers; 2003.

55. Van Meijl T. Maori socio-political organization in pre-and proto-history: on the evolution of post-colonial constructs. Oceania. 1995:304-22.

56. Steedman JAW: Nga ohaaki o nga whanau o Tauranga Moana - known genealogies and history of the Maori families of Tauranga and surrounding districts. Tauranga, J. A. W. Steedman; 1986.

57. Stafford DM: Te Arawa: a history of the Arawa people: reed; 1967.
58. McKenna A, Hanna M, Banks E, Sivachenko A, Cibulskis K, Kernytsky A, Garimella K, Altshuler D, Gabriel S, Daly M. The genome analysis toolkit: a MapReduce framework for analyzing next-generation DNA sequencing data. Genome Res. 2010;20(9):1297-303.

59. Li H: Aligning sequence reads, clone sequences and assembly contigs with BWA-MEM. arXiv preprint arXiv:13033997 2013.

60. Cingolani P, Platts A, Wang LL, Coon M, Nguyen T, Wang L, Land SJ, Lu X, Ruden DM. A program for annotating and predicting the effects of single nucleotide polymorphisms, SnpEff: SNPs in the genome of Drosophila melanogaster strain w1118; iso-2; iso-3. Fly. 2012;6(2):80-92.

61. Earl DA. STRUCTURE HARVESTER: a website and program for visualizing STRUCTURE output and implementing the Evanno method. Conserv Genet Resour. 2012:4(2):359-61.

62. Pritchard JK, Stephens M, Donnelly P. Inference of population structure using multilocus genotype data. Genetics. 2000;155(2):945-59.

63. Kopelman NM, Mayzel J, Jakobsson M, Rosenberg NA, Mayrose I. Clumpak: a program for identifying clustering modes and packaging population structure inferences across K. Mol Ecol Resour. 2015;15(5):1179-91.

64. Gusev A, Lowe J, Stoffel M, Daly M, Altshuler D, Breslow J, Friedman J, Pe'er I. Whole population, genome-wide mapping of hidden relatedness. Genome Res. 2009;19(2):318-26.

65. Leutenegger A-L, Prum B, Génin E, Verny C, Lemainque A, Clerget-Darpoux F, Thompson EA. Estimation of the inbreeding coefficient through use of genomic data. Am J Hum Genet. 2003;73(3):516-23.

66. Purcell S, Neale B, Todd-Brown K, Thomas L, Ferreira M, Bender D, Maller J, Sklar P, de Bakker P, Daly M, et al. Plink: a tool set for whole-genome association and population-based linkage analyses. Am J Hum Genet. 2007; 81(3):559-75.

67. R Core Team: R: A language and environment for statistical computing. In.: R Foundation for Statistical Computing, Vienna, Austria.; 2015.

68. StataCorp: Stata Statistical Software: Release 14. In.: College Station, TX: StataCorp LP; 2015.

69. Wald A: Sequential Tests of Statistical Hypotheses. 1945:117-186.

70. Vittinghoff E, Glidden D, Shiboski S, McCulloch C. Regression methods in biostatistics: linear, logistic, survival, and repeated measures models. New York: Springer; 2005.

71. Henn BM, Hon L, Macpherson JM, Eriksson N, Saxonov S, Pe'er I, Mountain $J$ L. Cryptic distant relatives are common in both isolated and cosmopolitan genetic samples. PLoS One. 2012;7(4):e34267.

72. Patterson N, Price AL, Reich D. Population structure and Eigenanalysis. PLoS Genet. 2006;2(12):e190

73. Khera AV, Won H-H, Peloso GM, Lawson KS, Bartz TM, Deng X, van Leeuwen EM, Natarajan P, Emdin CA, Bick AG. Diagnostic yield and clinical utility of sequencing familial hypercholesterolemia genes in patients with severe hypercholesterolemia. J Am Coll Cardiol. 2016;67(22):2578-89.

74. Bureau A, Parker MM, Ruczinski I, Taub MA, Marazita ML, Murray JC, Mangold E, Noethen MM, Ludwig KU, Hetmanski JB, et al. Whole exome sequencing of distant relatives in multiplex families implicates rare variants in candidate genes for Oral clefts. Genetics. 2014;197(3):1039-44.

75. NHLBI GO Exome Sequencing Project (ESP) [http://evs.gs.washington. edu/EVS/].

76. Sherry ST, Ward M-H, Kholodov M, Baker J, Phan L, Smigielski EM. Sirotkin K: dbSNP: the NCBI database of genetic variation. Nucleic Acids Res. 2001; 29(1):308-11.

77. Hubisz MJ, Pollard KS, Siepel A: PHAST and RPHAST: phylogenetic analysis with space/time models. Briefings in bioinformatics 2010:bbq072.

78. Wang K, Li M, Hakonarson H. ANNOVAR: functional annotation of genetic variants from high-throughput sequencing data. Nucleic Acids Res. 2010; 38(16):e164.

79. Yates A, Akanni W, Amode MR, Barrell D, Billis K, Carvalho-Silva D, Cummins C, Clapham P, Fitzgerald S, Gil L. Ensembl 2016. Nucleic Acids Res. 2015; 44(D1):D710-6.

80. Henderson P, Sutton E, Tayler R, Barclay A, Hansen R. PWE-137 the epidemiology and outcome of biliary atresia in Scotland 2002-2013. Gut. 2015;64(Suppl 1):A272-3.

81. Jakkula E, Rehnström $\mathrm{K}$, Varilo T, Pietiläinen $\mathrm{OPH}$, Paunio T, Pedersen NL, deFaire U, Järvelin M-R, Saharinen J, Freimer N, et al. The genome-wide patterns of variation expose significant substructure in a founder population. Am J Hum Genet. 2008;83(6):787-94.

82. Helgason A, Nicholson G, Stefánsson K, Donnelly P. A reassessment of genetic diversity in Icelanders: strong evidence from multiple loci for 
relative homogeneity caused by genetic drift. Ann Hum Genet. 2003; 67(4):281-97.

83. Scott EM, Halees A, Itan Y, Spencer EG, He Y, Azab MA, Gabriel SB, Belkadi A, Boisson B, Abel $L$, et al. Characterization of greater middle eastern genetic variation for enhanced disease gene discovery. Nat Genet. 2016;48(9):1071-6.

84. Yi N, Xu S. Bayesian mapping of quantitative trait loci for complex binary traits. Genetics. 2000;155(3):1391-403.

Ready to submit your research? Choose BMC and benefit from:

- fast, convenient online submission

- thorough peer review by experienced researchers in your field

- rapid publication on acceptance

- support for research data, including large and complex data types

- gold Open Access which fosters wider collaboration and increased citations

- maximum visibility for your research: over $100 \mathrm{M}$ website views per year

At $\mathrm{BMC}$, research is always in progress.

Learn more biomedcentral.com/submissions 